Supporting Information For:

\title{
Receptor for Anionic Pyrene Derivatives Provides the Basis for New Biomembrane Assays
}

\author{
Christine A. Winschel, Amar Kalidindi, Ibrahim Zgani, John L. Magruder and \\ Vladimir Sidorov* \\ Department of Chemistry, Virginia Commonwealth University, Richmond, VA 23284- \\ 2006
}

*Author to whom correspondence should be addressed.

\author{
Dr. Vladimir Sidorov \\ Assistant Professor \\ Department of Chemistry \\ Virginia Commonwealth University \\ 1001 West Main Street \\ Richmond, VA 23284-2006 \\ tel.: (804)828-7507 \\ e-mail: vasidorov@vcu.edu
}




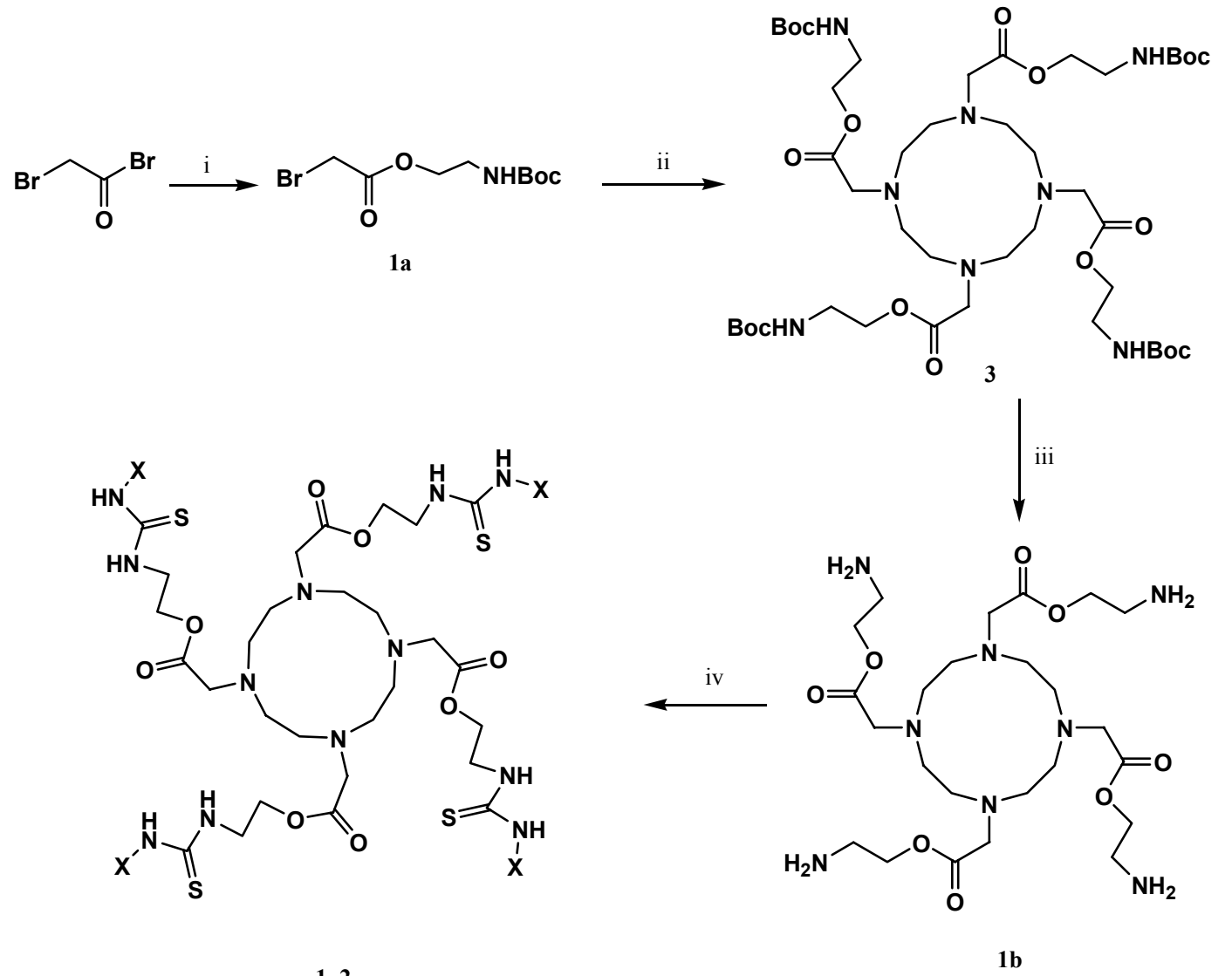

1, 2

Scheme S1. Synthesis of cyclen tetrathioureas. i) $t$-butyl-N-(2-hydroxyethyl)-

carbamate, $\mathrm{Et}_{3} \mathrm{~N}, \mathrm{CH}_{2} \mathrm{Cl}_{2}$, rt, 5 hrs; ii) cyclen, $\mathrm{CH}_{3} \mathrm{CN}$, rt, $72 \mathrm{hrs}$; iii) $\mathrm{TFA} / \mathrm{CH}_{2} \mathrm{Cl}_{2}, \mathrm{rt}, 6$ hrs; iv) a) $\mathrm{X}=1$-naphtyl:1-naphthyl isothiocyanate, $i-\mathrm{PrOH}, \mathrm{Et}_{3} \mathrm{~N}$, rt, 12 hrs. b) $\mathrm{X}=$ phenyl: phenylisothiocyanate, $i-\mathrm{PrOH}, \mathrm{Et}_{3} \mathrm{~N}, \mathrm{rt}, 12 \mathrm{hrs}$.

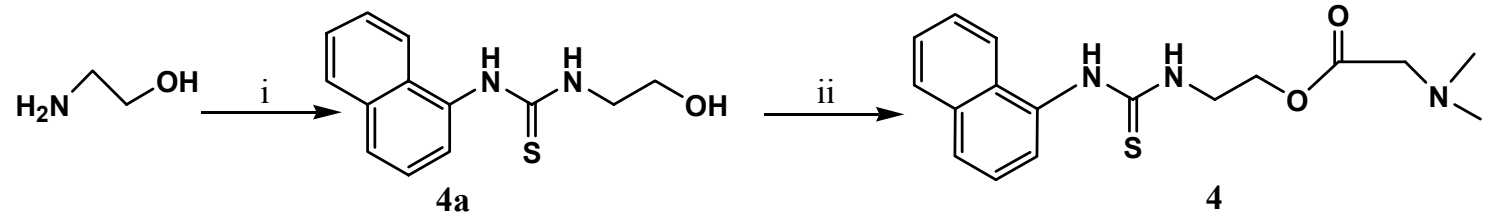

Scheme S2. Synthesis of monomer 4. i) 1-naphthyl isothiocyanate, ethyl acetate, rt, 20 min; ii) $\mathrm{N}, \mathrm{N}$-dimethylglycine, 1,1'-carbonyldiimidazole, $\mathrm{CH}_{2} \mathrm{Cl}_{2}, \mathrm{rt}, 15 \mathrm{hrs}$. 


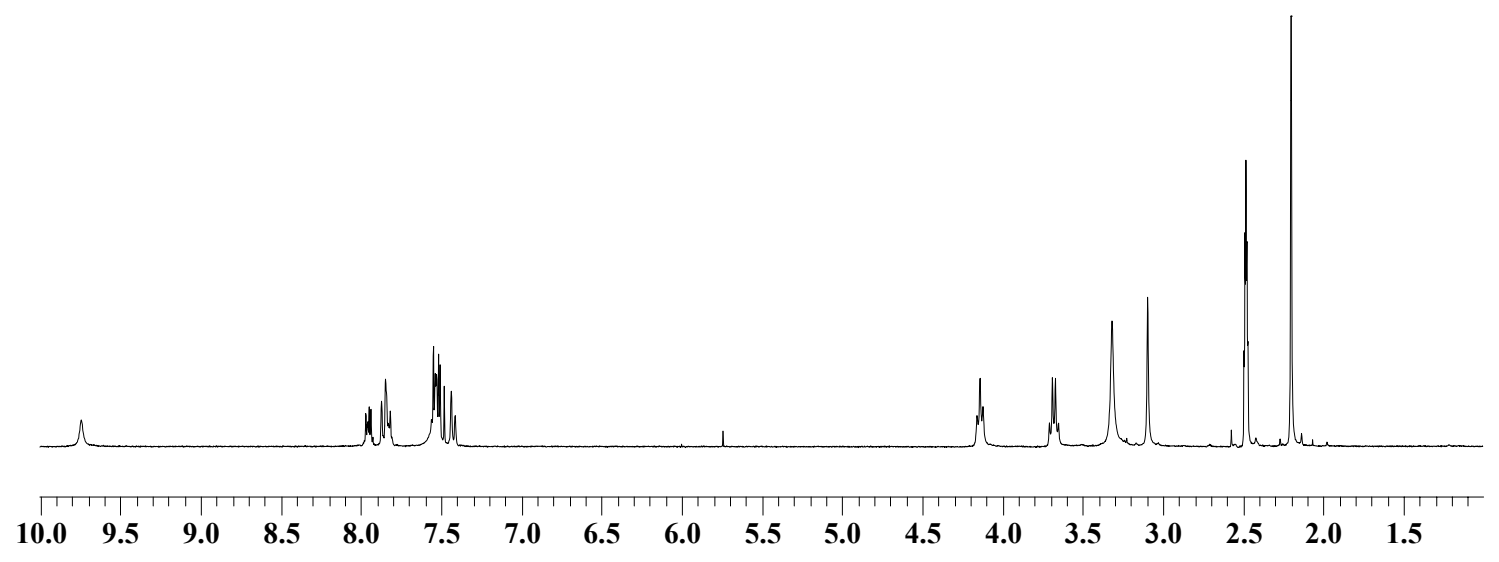

Figure S1. ${ }^{1} \mathrm{H}$ NMR spectrum of 4 in DMSO- $d_{6}$.

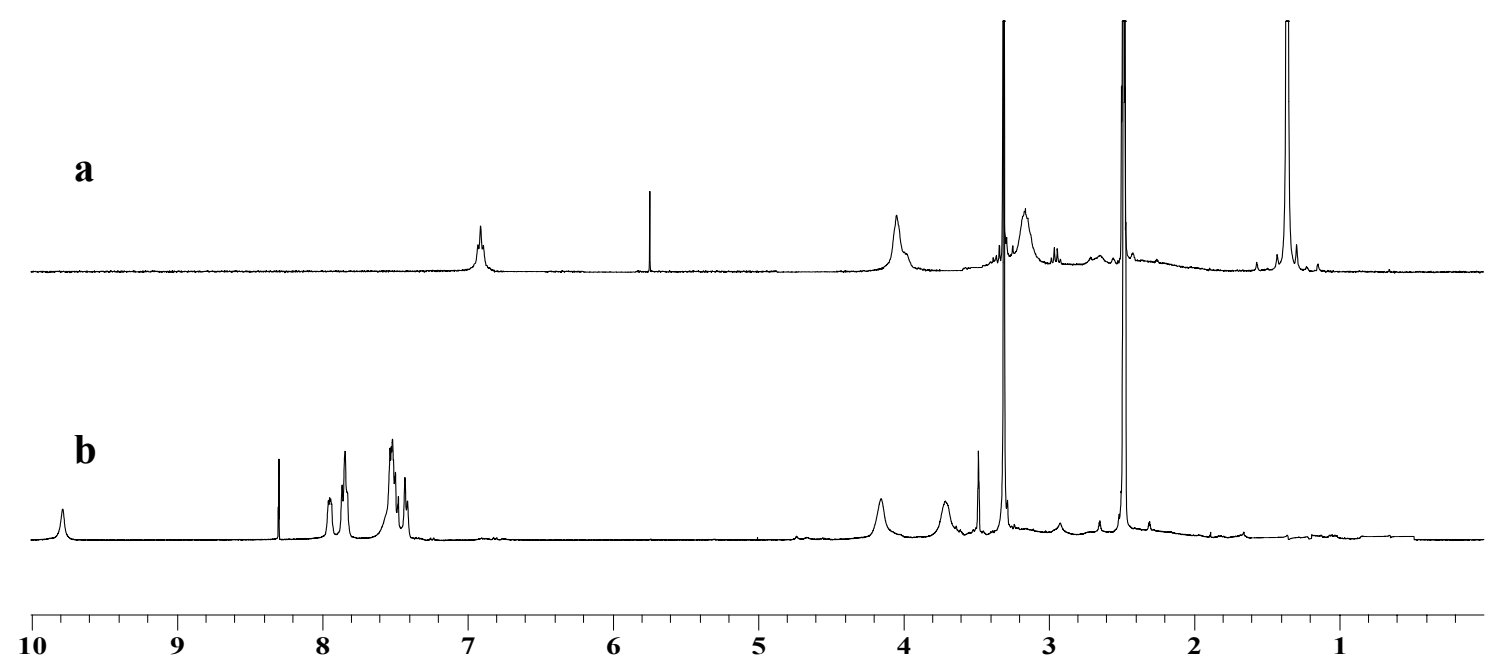

Figure S2. ${ }^{1} \mathrm{H}$ NMR spectra of a) cyclen NH-Boc 3 b) cyclen 1 in DMSO- $d_{6}$.

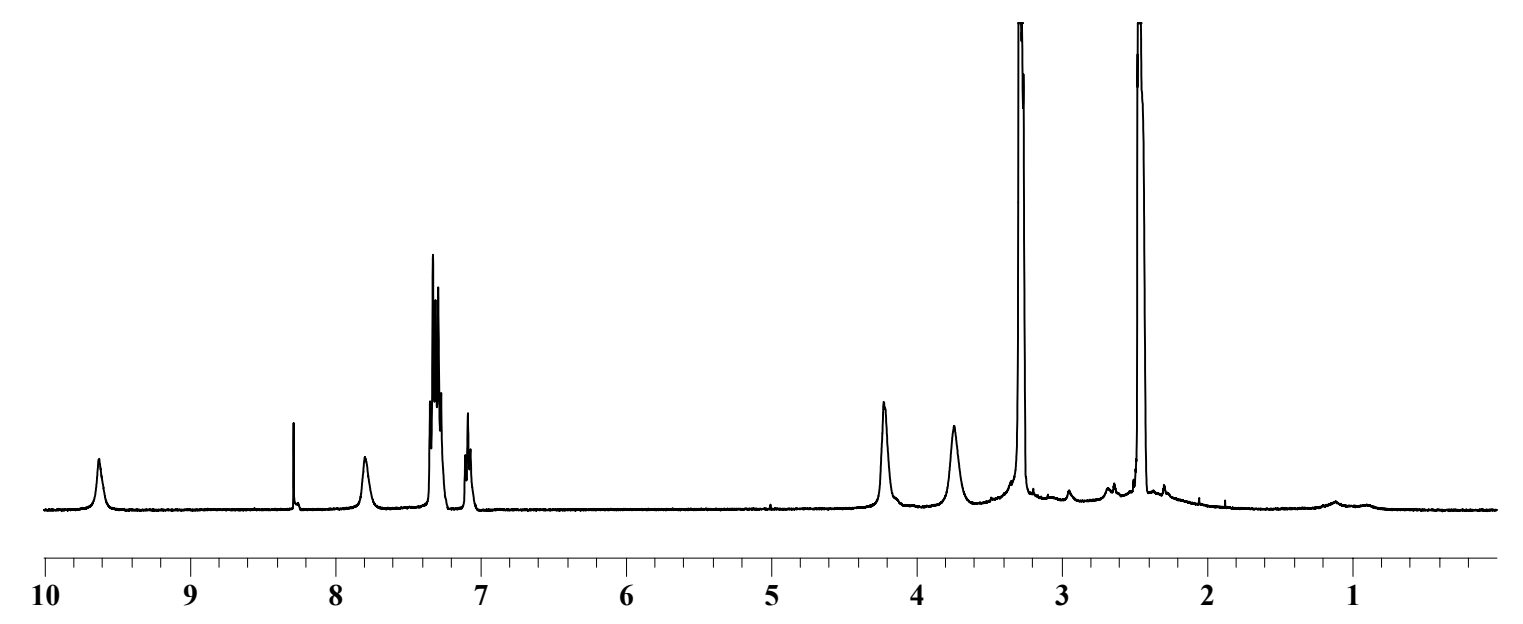

Figure S3. ${ }^{1} \mathrm{H}$ NMR spectrum of cyclen 2 in DMSO- $d_{6}$. 


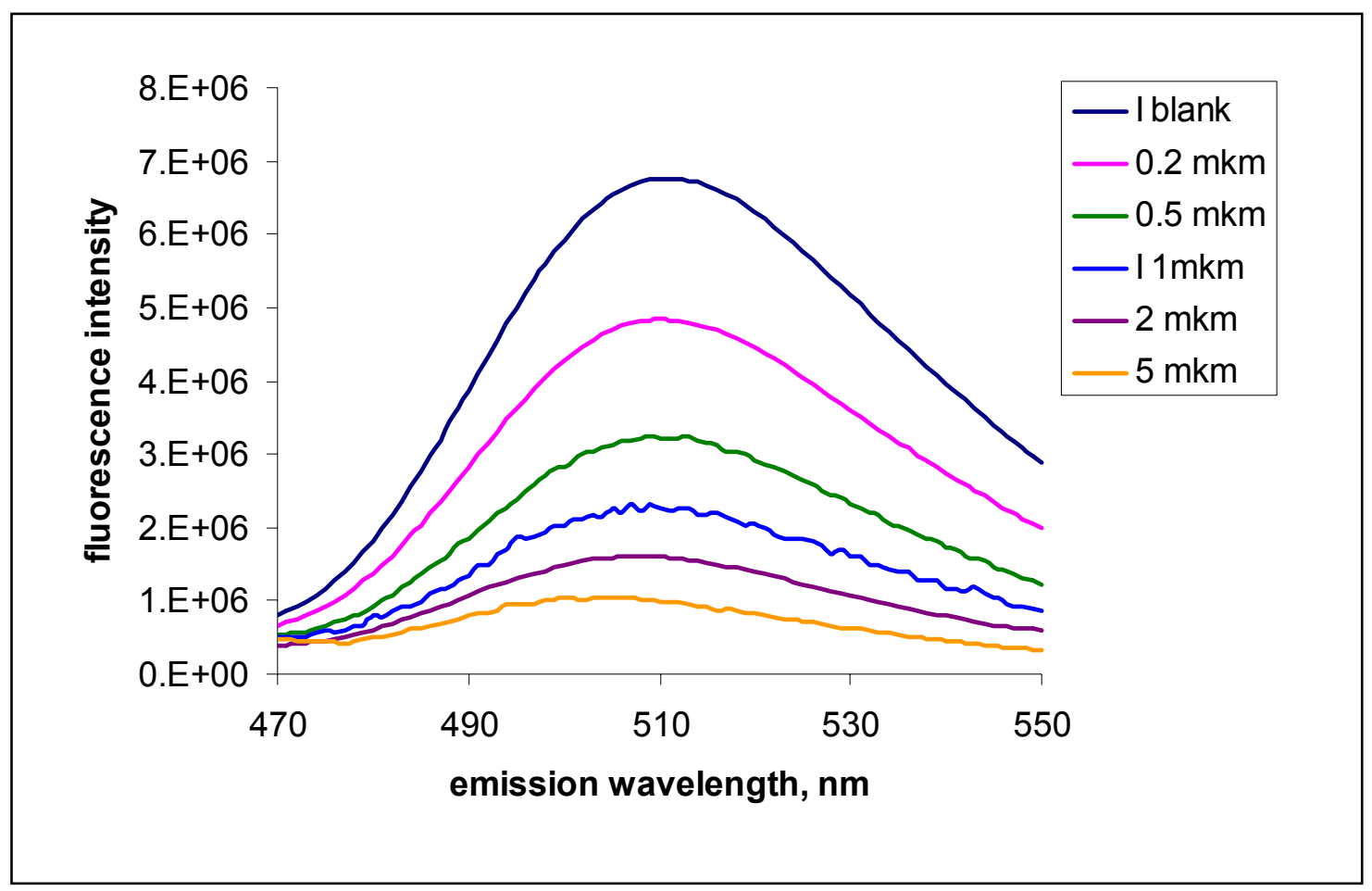

Figure S4. Raw fluorescence data for the titration of pyranine with cyclen $\mathbf{1}$. Concentration of pyranine was $50 \mathrm{nM}$. The spectra were recorded after $30 \mathrm{~min}$ upon addition of cyclen $\mathbf{1}$. The excitation wavelength was set at $405 \mathrm{~nm}$. Color code in the inset denotes bulk concentration of cyclen $\mathbf{1}$.

\begin{tabular}{|lcccccccc|}
\hline Dye & HPTS & APTS & PTA & ANTS & calcein & 5-CF & 6-CF & safranin O \\
\hline conc $^{\mathrm{a}}$ & 50 & 50 & 50 & 50 & 50 & 50 & 50 & 50 \\
Ex $^{\mathrm{b}}$ & 405 & 424 & 376 & 365 & 494 & 495 & 495 & 520 \\
$\mathrm{em}_{\max }$ & 510 & 503 & 403 & 515 & 520 & 518 & 515 & 580 \\
slits ex/em $^{\mathrm{d}}$ & $5 / 5$ & $4 / 4$ & $5 / 5$ & $5 / 5$ & $3 / 3$ & $3 / 3$ & $3 / 3$ & $7 / 7$ \\
\hline
\end{tabular}

Table S1. Experimental settings for the fluorometric titrations of different dyes with cyclen 1. a) concentration in $\mathrm{nM}$ in $\mathrm{PBS}+1 \% \mathrm{DMSO}$; b) excitation wavelength, $\mathrm{nm}$; c) emission maximum; d) monochromator slit openings, nm. 

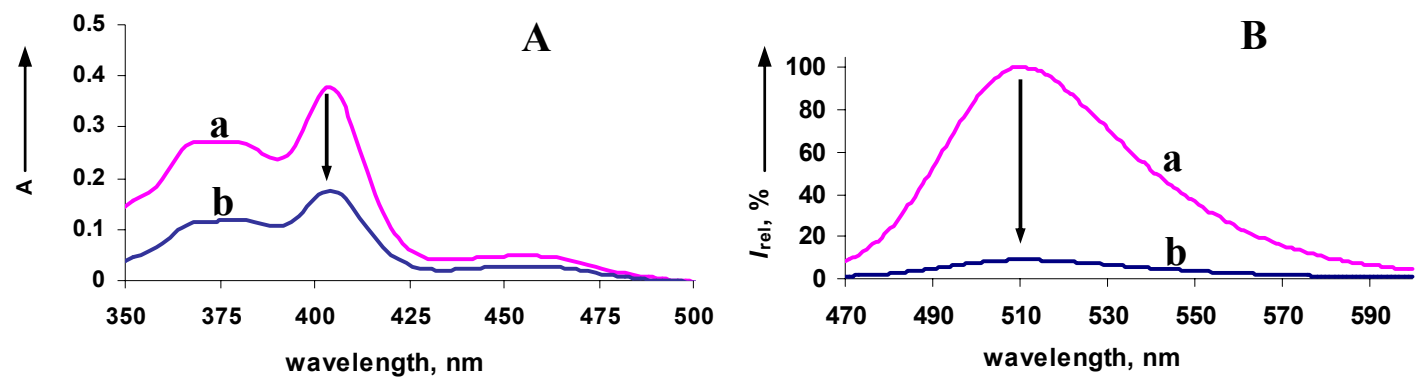

Figure S5. UV-VIS (A) and fluorescence $(\mathbf{B}$, ex $=405 \mathrm{~nm})$ spectra for: a) 20 $\mu \mathrm{M}$ solution of pyranine in $1 \%$ of DMSO in PBS. PBS with the same amount of DMSO was used as blank solution in UV-VIS; b) $20 \mu \mathrm{M}$ pyranine, $20 \mu \mathrm{M}$ cyclen 1 solution in $1 \%$ solution of DMSO in PBS. $20 \mu \mathrm{M}$ solution of cyclen 1 in $1 \%$ of DMSO in PBS was used as blank in UV-VIS. The arrow directions show the change of property upon complexation. $1 \mathrm{~cm}$ cell was used in UV-VIS experiment and $0.1 \mathrm{~cm}$ cell was used in fluorometric experiment (placed diagonally into the cell holder). 

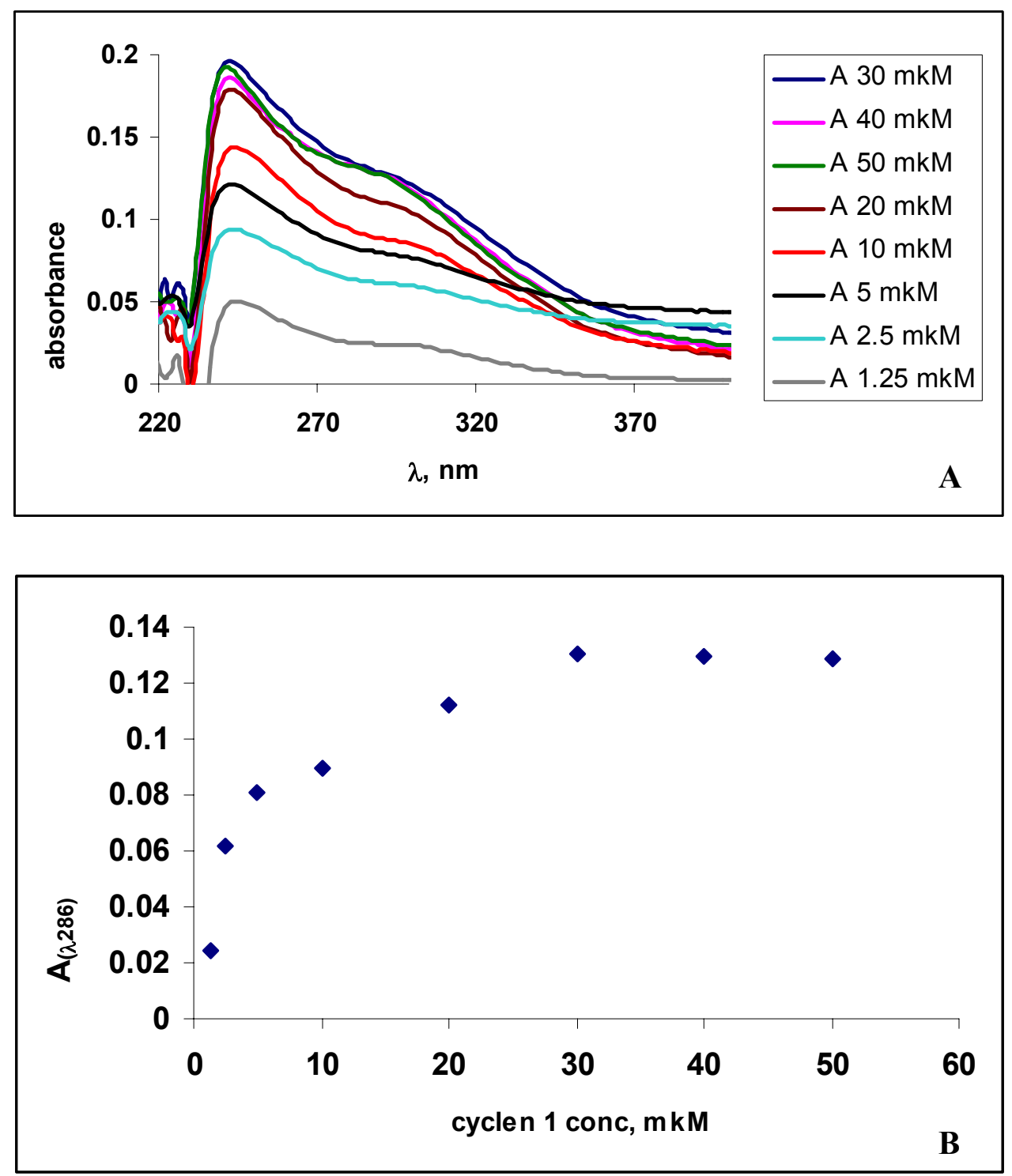

Figure S6. A. UV-VIS spectra of cyclen 1 solutions in PBS. Inset denotes concentrations of cyclen 1 for each individual trace. B. Plot of the absorbance $(\lambda=286$ $\mathrm{nm})$ as a function of cyclen $\mathbf{1}$ concentration for the series of cyclen $\mathbf{1}$ solutions in PBS. 